\title{
Prevention of exercise induced asthma by inhaled salmeterol xinafoate
}

\author{
C P Green, J F Price
}

\begin{abstract}
The effect of inhaled salmeterol xinafoate, a long acting $\beta_{2}$ agonist, on exercise induced asthma was studied in a double blind, crossover, and placebo controlled trial. Thirteen asthmatic children with a fall of at least $15 \%$ in their forced expiratory volume in one second $\left(F E V_{1}\right)$ after a standard exercise test on a motorised treadmill, on separate days performed the same test 1,5 , and 9 hours after a single dose of $50 \mu \mathrm{g}$ salmeterol or placebo. $\mathrm{FEV}_{1}$ was measured before treatment, and before and for $\mathbf{3 0}$ minutes after each exercise test. After placebo the number of children with exercise induced asthma was: 10 at 1 hour, 11 at 5 hours, and 12 at 9 hours. Salmeterol prevented exercise induced asthma in all 13 children studied, at 1, 5, and 9 hours. Mean maximum falls in FEV $_{1}$ after exercise were at 1 hour: salmeterol $2 \cdot 7 \%$ and placebo $24 \cdot 6 \%$, 5 hours: salmeterol $5.3 \%$ and placebo $22.7 \%$; and 9 hours: salmeterol 3.4\% and placebo $26.6 \%$. After salmeterol the mean increase in $\mathrm{FEV}_{1}$ was $17.8 \%$ at 1 hour, $19.6 \%$ at 5 hours, and $19.2 \%$ at 9 hours. Inhaled salmeterol prevents exercise induced asthma and produces significant bronchodilatation for at least 9 hours.
\end{abstract}

\section{(Arch Dis Child 1992;67:1014-1017)}

Exercise is a common problem for children with asthma, who tend to be more physically active than adults. Over $70 \%$ of asthmatic children studied with treadmill exercise tests have exercise induced asthma, ${ }^{12}$ and $98 \%$ of children attending an asthma clinic complained of symptoms on exercise. ${ }^{3}$

The airway response to exercise is a measure of indirect bronchial responsiveness; the mechanism is not fully understood but probably involves bronchial smooth muscle cells, mast cells, and neurons ${ }^{45}$ with the release of mediators. $^{5-7}$ This response to exercise has been used to assess the efficacy and duration of action of asthma treatments. ${ }^{3}$ Inhaled $\beta_{2}$ adrenoceptor agonists are the most effective drugs for the prevention of exercise induced asthma when taken five to 15 minutes before exercise. ${ }^{8-10}$ This protective effect, however, lasts for only two hours in the majority of asthmatics ${ }^{7}{ }^{11}$ and the duration varies widely. ${ }^{8} 12$

Salmeterol xinafoate is a long acting $\beta_{2}$ adrenoceptor agonist. It has a polar phenylethanolamine head which binds reversibly to the $\beta_{2}$ receptor. ${ }^{13}$ In addition to this it has a long non-polar side chain which is thought to bind to the cell membrane adjacent to the $\beta_{2}$ receptor. ${ }^{14}$
It has been shown to inhibit in vitro constriction of airway smooth muscle ${ }^{15}$ and the release of mediators from mast cells. ${ }^{13}$ It produces prolonged bronchodilatation in adult asthmatic patients. ${ }^{14}$ The long duration of effect is attributed to an action of the long non-polar side chain. Salmeterol also ablates both the early and late bronchial reaction and the increase in bronchial responsiveness that follows allergen challenge. ${ }^{16}$

There are no published data on the effect of salmeterol in exercise induced asthma or of its use in children. Our aim was to study the effect of a single dose of inhaled salmeterol on exercise induced asthma in children. It has been shown in previous studies that the degree of bronchoconstriction after exercise is reproducible ${ }^{1}$ and does not alter significantly with repetition, at intervals of greater than two hours, during the day. ${ }^{3}$ We therefore investigated the response to exercise in a group of asthmatic children 1, 5, and 9 hours after a single morning dose of salmeterol. The study was placebo controlled because placebo has been shown to reduce significantly exercise induced asthma in up to $40 \%$ of children. ${ }^{17}$

\section{Methods}

TRIAL DESIGN

The study was double blind, randomised, crossover, and placebo controlled. Children attending the paediatric asthma clinic at King's College Hospital who gave a clear history of exercise induced cough or wheeze and who were proficient in spirometry, were recruited. The parents gave informed consent for their children to participate and the study was approved by the hospital ethical committee. We calculated from a previous study of exercise induced asthma in children ${ }^{1}$ that to detect a $20 \%$ difference in the mean maximum fall in forced expiratory volume in one second $\left(\mathrm{FEV}_{1}\right)$ after exercise between salmeterol and placebo with $90 \%$ power at the $5 \%$ level we would require a sample size of 13 patients.

Each child attended the paediatric respiratory laboratory for an initial exercise test. All medication except inhaled steroids was stopped for at least 12 hours beforehand. FEV 1 was measured in a Jaeger Bodytest reverse plethysmograph, with a capacity of 800 litres, checked against a IL calibration syringe on each occasion. This system was used because many of the children were already familiar with it, the scale could be easily adjusted for different sized children, and for its convenience in making multiple recordings. 
If the baseline $\mathrm{FEV}_{1}$ was greater than $60 \%$ of the mean predicted for the child's height ${ }^{18}$ the exercise test was done. This consisted of continuous running on a motorised treadmill for two minutes at 5 degrees upward inclination and a speed of 2.5 kilometres per hour $(\mathrm{kph})$, followed by six minutes at 10 degrees and $5 \mathrm{kph}$.

Heart rate was measured before and immediately after the running period and then $\mathrm{FEV}_{1}$ was measured every three minutes for 15 minutes and every five minutes for a further 15 minutes. The maximum percentage fall in $\mathrm{FEV}_{1}$ from baseline was calculated. Children who attained a pulse rate of at least 170 beats per minute (bpm) and had a fall in $\mathrm{FEV}_{1}$ of at least $15 \%$ after exercise were entered into the study.

The children who fulfilled the entry criteria attended the laboratory on two more occasions, which were not less than four and not more than 10 days apart. On each occasion medication was withheld as before. $\mathrm{FEV}_{1}$ was measured and provided this was within $15 \%$ of the previous baseline value the study proceeded.

Either $50 \mu \mathrm{g}$ salmeterol or placebo were administered as aerosols via a large volume spacer device (Volumatic, Allen and Hanburys $^{19}$ ). Exercise tests using the same settings as in the initial test and with the same measurements of heart rate and $\mathrm{FEV}_{1}$ were done 1,5 , and 9 hours later.

\section{ANALYSIS OF DATA}

Group data was expressed as means and 95\% confidence intervals (CI). Parametric analyses were used only when normal distribution of data had been established. The pretreatment values of $F E V_{1}$ were compared using the paired $t$ test. Baseline FEV 1 before the initial exercise test and pretreatment $\mathrm{FEV}_{1}$ on the two study days were compared using a two way analysis of variance (ANOVA) with patient and study day as factors. Factors influencing maximum fall in $\mathrm{FEV}_{1}$ after exercise and change in $\mathrm{FEV}_{1}$ after treatment were analysed by multiple regression analysis of patient, pretreatment $\mathrm{FEV}_{1}$, treatment, treatment order, and time point after treatment. The maximum falls in $\mathrm{FEV}_{1}$ after exercise at 1, 5, and 9 hours after salmeterol were compared with placebo using paired $t$ tests, including the Bonferroni adjustment. ${ }^{20}$ Two way ANOVA was used to compare the maximum falls after exercise 1,5 , and 9 hours

Table 1 Maximum percentage fall in FEV, after exercise

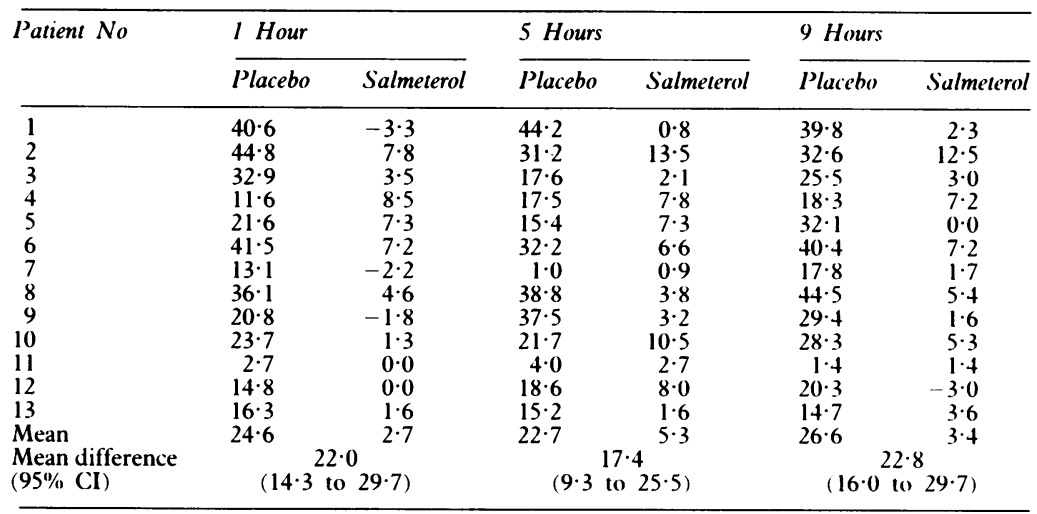

after each treatment (salmeterol or placebo) with patient and time after treatment as factors. The change from baseline in values of $F V_{1}$ before exercise on each study day and at each time point were compared using two way ANOVA. On the day salmeterol was given, $F E V_{1}$ before treatment and $F E V_{1}$ before each of the exercise tests were compared by two way ANOVA. Heart rate before treatment and before each of the exercise tests was analysed for treatment effect using two way ANOVA. For the placebo study day the same analyses were performed.

\section{Patients}

Thirteen children, five girls and eight boys, aged 8 to 15 (mean 12) years fulfilled the entry criteria and completed the study. All were taking an inhaled bronchodilator as required, two were also taking sodium cromoglycate, seven inhaled steroids, and one theophylline. The children remained well and free of respiratory tract infections or exacerbations of their asthma for the duration of the study.

\section{Results}

Baseline values for $\mathrm{FEV}_{1}$ at the first visit were from $66 \%$ to $104 \%$ of predicted (mean $87 \%$ ). There was no difference between the pretreatment $\mathrm{FEV}_{1}$ values for the two study days $(p=0 \cdot 24)$ and no difference between the initial values for $\mathrm{FEV}_{1}$ on the three visits $(\mathrm{p}>0 \cdot 25)$.

The only significant factors for fall in $\mathrm{FEV}_{1}$ after exercise were treatment $(p<0.001)$ and patient $(p<0.001)$. When the children were treated with salmeterol they had a significantly smaller fall in $\mathrm{FEV}_{1}$ after exercise at 1 hour $(\mathrm{p}<0.0003)$, at 5 hours $(\mathrm{p}<0.0015)$, and at 9 hours $(p<0.0003)$ than when given placebo. After salmeterol there were no children who had a fall in $\mathrm{FEV}_{1}$ of greater than $15 \%$ during exercise tests at $\mathbf{1}$, at 5 and at 9 hours. After placebo the number of children with a fall in $\mathrm{FEV}_{1}$ of greater than $15 \%$ was 10 at 1 hour, 11 at 5 hours, and 12 at 9 hours (table 1). The degree and duration of bronchoconstriction after 1,5 , and 9 hours was very consistent on the day each child was given placebo $(p>0 \cdot 1)$. When salmeterol was given there was complete inhibition of bronchoconstriction at each time point with no diminution of effect over 9 hours ( $p>0.05$; figure).

Multiple regression analysis showed the only significant factors for change in $\mathrm{FEV}_{1}$ after treatment were treatment $(p<0.001)$ and patient $(p<0.001)$. Salmeterol caused a significant increase in $\mathrm{FEV}_{1}$ before exercise at 1,5 , and 9 hours $(p<0.001)$. This increase was similar before each exercise test $(p<0 \cdot 25)$. On the placebo study day there was no difference between the baseline and values for $F_{1}$ before exercise ( $p>0.25$; table 2$)$.

There was no difference between the heart rates before treatment and before exercise on the salmeterol study day $(p>0.05)$ or the placebo study day $(\mathrm{p}>0 \cdot 25)$. Mean heart rate before treatment on the salmeterol study day was $88 \cdot 5$ (CI $77 \cdot 6$ to $92 \cdot 5$ ). The mean heart rates 
- Salmeterol Placebo
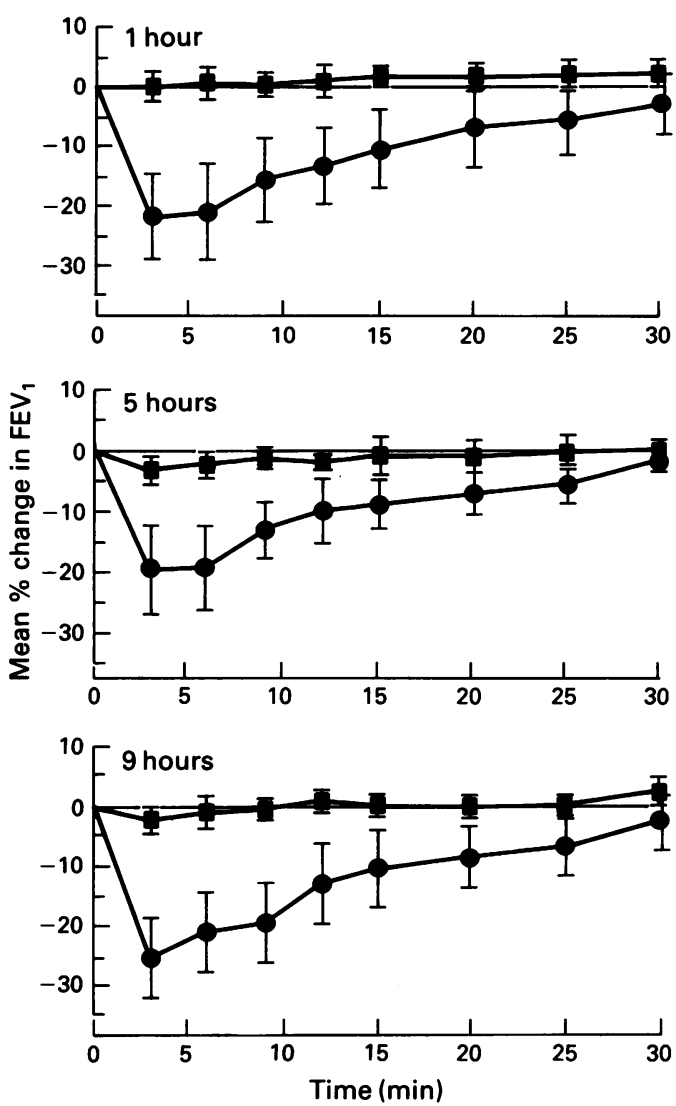

Change in FEV, after exercise. Bars show 95\% CI.

(bpm) before exercise were $89 \cdot 2$ (CI 82.4 to $96 \cdot 1$ ) at 1 hour, $92 \cdot 2$ (CI $85 \cdot 8$ to $98 \cdot 5$ ) at 5 hours, and $95 \cdot 2$ (CI $89 \cdot 8$ to $100 \cdot 7$ ) at 9 hours. Mean heart rate before treatment on the placebo study day was 88.5 (CI 82.4 to 94.6 ). The mean heart rates before exercise were $85 \cdot 1$ (CI $77 \cdot 6$ to 92.5 ) at 1 hour, 89.1 (CI 82.8 to 95.3 ) at 5 hours, and 88.9 (CI 82.8 to 95.0 ) at 9 hours. No adverse effects were seen.

\section{Discussion}

Our results confirm that the technique of repeated exercise tests on a single study day is reproducible. The mean of the individual coefficient of variation for the maximal percent fall in $\mathrm{FEV}_{1}$ after the three exercise tests on the

Table 2 Percentage increase in FEV, before each exercise test (from pretreatment baseline)

\begin{tabular}{|c|c|c|c|c|c|c|}
\hline \multirow[t]{2}{*}{ Patient No } & \multicolumn{2}{|l|}{1 Hour } & \multicolumn{2}{|l|}{5 Hours } & \multicolumn{2}{|l|}{9 Hours } \\
\hline & Placebo & Salmeterol & Placebo & Salmeterol & Placebo & Sulmeterol \\
\hline $\begin{array}{l}1 \\
2 \\
3 \\
4 \\
5 \\
6 \\
7 \\
8 \\
9 \\
10 \\
11 \\
12 \\
13 \\
\text { Mean } \\
\text { Mean difference } \\
\text { (95\% CI) }\end{array}$ & $\begin{array}{r}-0 \cdot 0 \\
15 \cdot 9 \\
1 \cdot 8 \\
8 \cdot 8 \\
-3 \cdot 4 \\
0 \cdot 0 \\
11 \cdot 5 \\
6.6 \\
8 \cdot 2 \\
-1 \cdot 7 \\
1 \cdot 4 \\
10 \cdot 4 \\
0.6 \\
4 \cdot 6 \\
\end{array}$ & $\begin{array}{r}16 \cdot 5 \\
39 \cdot 6 \\
7 \cdot 5 \\
30 \cdot 1 \\
14 \cdot 9 \\
37 \cdot 4 \\
20 \cdot 4 \\
44 \cdot 4 \\
7 \cdot 8 \\
8 \cdot 8 \\
0 \cdot 0 \\
4 \cdot 4 \\
0 \cdot 0 \\
17 \cdot 8 \\
21 \cdot 8)\end{array}$ & $\begin{array}{r}9 \cdot 0 \\
0 \cdot 0 \\
10 \cdot 3 \\
7 \cdot 6 \\
7 \cdot 7 \\
5 \cdot 3 \\
6 \cdot 3 \\
-19 \cdot 2 \\
6 \cdot 1 \\
0 \cdot 0 \\
4 \cdot 1 \\
7 \cdot 4 \\
4 \cdot 0 \\
3 \cdot 7 \\
\\
4 \cdot 9\end{array}$ & $\begin{array}{r}20 \cdot 3 \\
35 \cdot 9 \\
2 \cdot 7 \\
25 \cdot 2 \\
15 \cdot 7 \\
42 \cdot 1 \\
25 \cdot 3 \\
39 \cdot 1 \\
21 \cdot 6 \\
11 \cdot 7 \\
6 \cdot 6 \\
10 \cdot 2 \\
0 \cdot 0 \\
19 \cdot 6 \\
27 \cdot 1)\end{array}$ & $\begin{array}{r}9 \cdot 0 \\
7 \cdot 7 \\
1 \cdot 2 \\
13 \cdot 2 \\
10 \cdot 2 \\
4 \cdot 1 \\
8 \cdot 3 \\
-5 \cdot 0 \\
-6 \cdot 1 \\
0 \cdot 0 \\
-4 \cdot 1 \\
5 \cdot 9 \\
0 \cdot 0 \\
3 \cdot 4 \\
\\
\end{array}$ & $\begin{array}{r}23 \cdot 1 \\
39 \cdot 6 \\
6 \cdot 9 \\
19 \cdot 0 \\
17 \cdot 3 \\
37 \cdot 4 \\
26 \cdot 3 \\
47 \cdot 0 \\
21 \cdot 6 \\
10 \cdot 2 \\
1 \cdot 4 \\
1 \cdot 5 \\
1 \cdot 0 \\
19 \cdot 2 \\
25 \cdot 6)\end{array}$ \\
\hline
\end{tabular}

placebo study day was $25 \cdot 5 \%$; this is similar to previous studies. ${ }^{1} 67$ There was a placebo effect in some children. The maximal fall in $\mathrm{FEV}_{1}$ was reduced by more than $15 \%$ in at least a third of the children after each of the exercise tests on the placebo study day (5/13 at 1 hour, $7 / 13$ at 5 hours, and $7 / 13$ at 9 hours). The effect of placebo on exercise induced asthma has been noted before. ${ }^{17}$ In our study the effect on the group as a whole was small and analysis by two way ANOVA of the maximal fall in $\mathrm{FEV}_{1}$ after the initial entry exercise test and after the three exercise tests on the placebo study day did not show a difference $(\mathrm{p}>0.01)$.

The duration of inhibition of exercise induced asthma in children by inhaled salmeterol xinafoate in this study (at least 9 hours) exceeds that reported in studies of other $\beta_{2}$ agonists. Though the exact mechanisms by which $\beta_{2}$ agonists protect against exercise induced asthma are unclear, it is not apparently related to their bronchodilator effect as bronchodilatation is still present at a time when there is no longer any protective effect against exercise induced asthma. ${ }^{711} 21$ In our study bronchodilatation was present before each exercise test so it was not possible to exclude bronchodilatation as an alternative cause of the protection from exercise induced asthma. To resolve this question a study with exercise tests at later time points after treatment would be needed. Raised concentrations of inflammatory mediators have been demonstrated after exercise, ${ }^{22}$ and inhibition of mediator release is a possible mechanism for the prevention of exercise induced asthma. ${ }^{12} 23$ Salmeterol has been shown to block the early and late response to inhaled allergen, suggesting an effect extending beyond a protective action on airways smooth muscle. ${ }^{16}$

Tachycardia is a known side effect of $\beta_{2}$ agonists, ${ }^{24}$ but in the dose administered there was no significant increase in heart rate before exercise after inhaled salmeterol (two way ANOVA $p>0.05$ ). Concern has been expressed recently about the regular use of $\beta_{2}$ agonists, particularly as a recent study has found regular use of inhaled fenoterol is associated with deterioration of asthma control. ${ }^{25}$ Studies with salmeterol have not shown any deterioration of asthma control ${ }^{26}{ }^{27}$ so the effect observed with fenoterol may not apply to all $\beta_{2}$ agonists. ${ }^{28}$ It is unlikely that concern over regular usage of $\beta_{2}$ agonists will apply to their intermittent use on days when vigorous exercise is anticipated.

Asthmatic children, even when receiving regular prophylaxis, may still need pretreatment with an inhaled $\beta_{2}$ agonist to inhibit exercise induced asthma. ${ }^{6}$ The main disadvantage of current $\beta_{2}$ agonists is their short duration of action. As organised school sporting activities take place during the afternoon, prevention of exercise induced asthma during these activities relies on asthmatic children taking their treatment at school. A recent study of school teachers in London showed limited understanding of asthma, with only half answering that they should ensure that necessary drugs are taken before games. In addition only half of the teachers would allow asthmatic children to keep their medicines with them. ${ }^{29}$ This may 
compound the difficulties facing children who ought to be taking prophylaxis against exercise induced asthma before sport. Physical activities are useful to asthmatic children and appropriate prophylactic treatment by $\beta$ adrenergic agents will usually permit full participation. ${ }^{30}$ In addition efforts should be made to enhance the child's feelings of self worth and avoid feelings of being different from other children. ${ }^{30}$

A single dose of salmeterol xinafoate could be given by a parent in the morning on a day in which sporting activities were anticipated. This would avoid the need for the child to take or be given a dose before exercise. This would also remove any peer pressure attendant on their being seen to take an inhaler at school.

We are grateful to Children Nationwide medical research fund for supporting CPG and to Glaxo Group Research for providing for supporting
the materials.

1 Silverman M, Anderson SD. Standardisation of exercise tests in asthmatic children. Arch Dis Child 1972;47:882-9.

2 Kattan M, Keens TG, Mellis CM, Levison H. The response to attan M, Keens TG, Mellis CM, Levison H. The response to
exercise in normal and asthmatic children. $\mathcal{J}$ Pediatr 1978 ; 92:718-21.

3 Silverman M, Konig P, Godfrey S. Use of serial exercise tests to assess the efficacy and duration of action of drugs for asthma. Thorax 1973;28:574-8.

4 Pauwels R, Joos G, Van der Straeten M. Bronchial hyperresponsiveness is not bronchial asthma. Clinical Allergy 1988;18:317-21.

5 Cropp G. Exercise-induced asthma. Pediatr Clin North Am 1975;22:63-76.

6 Godfrey S. Exercise-induced asthma. Arch Dis Child 1983;58: $1-2$.

7 Wooley M, Anderson SD, Quigley BM. Duration of protective effect of terbutaline sulphate and cromolyn sodium alone and in combination on exercise-induced asthma. Chest and in combinatic $1990 ; 97: 39-45$.

8 Berkowitz R, Schwartz E, Bukstein MD, Grunstein M, Chai $\mathrm{H}$. Albuterol (salbutamol) protects against exercise-induced asthma longer than metaproterenol sulphate. Pediatrics 1986;77:173-9.

9 Anderson S, Seale JP, Ferris L, Scheffel R, Lindsay DA. An evaluation of pharmacotherapy for exercise-induced asthma. f Allergy Clin Immunol 1979;64:612-24.

10 Godfrey S, Konig P. Inhibition of exercise-induced asthma by different pharmacological pathways. Thorax 1976;31: $137-43$

11 Konig P, Hordvik BS, Serby CW. Fenoterol in exerciseinduced asthma: effect of dose on efficacy and duration of action. Chest 1984;85:462-4.

12 Higgs CMB, Laszlo $G$. The duration of protection from exercise-induced asthma by inhaled salbutamol, and a comparison with inhaled reproterol. British foumal of Comparison with inhaled reproter

13 Butchers PR, Cousins SA, Vardey CJ. Salmeterol: a potent and long-acting inhibitor of the release of inflammatory and spasmorgenic mediators from human lung. Br. F Pharmacol 1987;92 (suppl):745P.

14 Ullman A, Svedmyr N. Salmeterol, a new long acting inhaled $B_{2}$ adrenoceptor agonist: comparison with salbutamol in adult asthmatic patients. Thorax 1988;43:674-8.

15 Johnson M. The pharmacology of salmeterol. Lung, 1990;168 (suppl): 115-9.

16 Twentyman OP, Finnerty JP, Harris A, Palmer J, Holgate ST. Protection against allergen-induced asthma by ST. Protection against allergen-ind

17 Godfrey S, Silverman M. Demonstration of placebo response in asthma by means of exercise testing. f Psychosom Res in asthma by

18 Cogswell JJ, Hull D, Milner AD, Norman AP, Taylor B. Lung function in childhood. British fournal of Diseases of the Chest 1975;69:40-50.

19 Green CP, Price JF. Bronchodilator effect of salbutamol via the Volumatic in children. Respir Med 1991;85:325-6.

20 Altman DG. Practical statistics for medical research. London: Chapman and Hall, 1991:211.

21 McAlpine LG, Thomson NC. Prophylaxis of exercise-induced asthma with inhaled formoterol, a long-acting $\beta_{2}$ adrenergic agonist. Respir Med 1990;84:293-5.

22 Lee TH, Nagakura T, Papageorgiou N, Cromwell O, Likura Y, Kay AB. Mediators in exercise-induced asthma. Y, Kay AB. Mediators in exercise

23 Hetzel MR, Batten JC, Clark TJH. Do sympathomimetic amines prevent exercise-induced asthma by bronchodilatation alone? British Journal of Diseases of the Chest 1977;71: 109-14.

24 BMA and Pharmaceutical Society of Great Britain. British national formulary. No 21. London: BMA and Pharmaceutical Society of Great Britain, 1991:101.

25 Sears MR, Taylor DR, Print CG, et al. Regular inhaled agonist treatment in bronchial asthma. Lancet 1990;336: 1391-6.

26 Lundback B, Lindstrom $M$. A 3 month comparison of salmeterol and salbutamol dry powder. Clin Exp Allergy 1990;20 (suppl 1):38, P93.

27 Britton M. Salmeterol: three month comparison with salbutamol in asthmatic patients. Eur Resp F 1990;3 (suppl 10);226-S797.

28 Crane J, Burgess C, Beasley R, Pearce N. B, agonists in asthma. Lancet 1991;337:44.

29 Bevis M. Taylor B. What do school teachers know about asthma? Arch Dis Child 1990;65:622-5.

30 Committee on Children with Disabilities and Committee on Sports medicine. The asthmatic child's participation in sports and physical education. Pediatrics 1984;74:155-6. 